\title{
Do empowered stroke patients perform better at self-management and functional recovery after a stroke? A randomized controlled trial
}

This article was published in the following Dove Press journal:

Clinical Interventions in Aging

13 October 2016

Number of times this article has been viewed

\author{
Janet WH Sit ${ }^{\prime}$ \\ Sek Ying Chair' \\ Kai Chow Choi' \\ Carmen WH Chan' \\ Diana TF Lee' \\ Aileen WK Chan' \\ Jo LK Cheung' \\ Siu Wai Tang ${ }^{2}$ \\ Po Shan Chan ${ }^{2}$ \\ Ruth E Taylor-Piliae 3 \\ 'The Nethersole School of Nursing, \\ The Chinese University of Hong Kong, \\ Shatin, New Territories, ${ }^{2}$ Department \\ of Medicine and Rehabilitation, \\ Tung Wah Eastern Hospital, Hong \\ Kong Hospital Authority, Causeway \\ Bay, Hong Kong, People's Republic \\ of China; ${ }^{3}$ College of Nursing, The \\ University of Arizona, Tucson, AZ, USA
}

Background: Self-management after a stroke is a challenge because of multifaceted care needs and complex disabling consequences that cause further hindrance to patient participation. A 13-week stroke patient empowerment intervention (Health Empowerment Intervention for Stroke Self-management [HEISS]) was developed to enhance patients' ability to participate in self-management.

Purpose: To examine the effects of the empowerment intervention on stroke patients' selfefficacy, self-management behavior, and functional recovery.

Methods: This is a single-blind randomized controlled trial with stroke survivors assigned to either a control group (CG) receiving usual ambulatory rehabilitation care or the HEISS in addition to usual care (intervention group [IG]). Outcome data were collected at baseline (T0), 1 week (T1), 3 months (T2), and 6 months (T3) postintervention. Data were analyzed on the intention-to-treat principle. The generalized estimating equation model was used to assess the differential change of self-efficacy in illness management, self-management behaviors (cognitive symptom management, communication with physician, medication adherence, and self-blood pressure monitoring), and functional recovery (Barthel and Lawton indices) across time points (baseline $=\mathrm{T} 0,1$ week $=\mathrm{T} 1,3$ months $=\mathrm{T} 2$, and 6 months $=\mathrm{T} 3$ postintervention $)$ between the two groups.

Results: A total of 210 ( $\mathrm{CG}=105, \mathrm{IG}=105)$ Hong Kong Chinese stroke survivors (mean age $=69$ years, $49 \%$ women, $72 \%$ ischemic stroke, $89 \%$ hemiparesis, and $63 \%$ tactile sensory deficit) were enrolled in the study. Those in IG reported better self-efficacy in illness management 3-month $(P=0.011)$ and 6-month $(P=0.012)$ postintervention, along with better self-management behaviors at all follow-up time points (all $P<0.05$ ), apart from medication adherence $(P>0.05)$. Those in IG had significantly better functional recovery (Barthel, all $P<0.05$; Lawton, all $P<0.001$ ), compared to CG. The overall dropout rate was $16.7 \%$.

Conclusion: Patient empowerment intervention (HEISS) may influence self-efficacy in illness management and improve self-management behavior and functional recovery of stroke survivors. Furthermore, the HEISS can be conducted in parallel with existing ambulatory stroke rehabilitation services and provide added value in sustaining stroke self-management and functional improvement in the long term.

Keywords: self-management, patient empowerment, stroke, rehabilitation, functional recovery, activities of daily living

\section{Introduction}

The Nethersole School of Nursing, The Chinese University of Hong Kong, Shatin, New Territories, Hong Kong, People's Republic of China

Email janet.sit@cuhk.edu.hk
Neurological and neuropsychiatric conditions, such as traumatic brain injury, Parkinson's disease, dementia, and stroke, are often characterized by considerable deficits that significantly reduce patients' functional abilities and their overall quality 
of life. Particularly, stroke is a major cause of long-term disability worldwide, representing a substantial health care burden. ${ }^{1}$ In Hong Kong, there are $\sim 16,000$ new stroke cases, with $>3,000$ deaths each year. ${ }^{2}$ People living with stroke face enormous challenges in physical, psychological, and social aspects of their lives throughout the poststroke recovery period. Stroke survivors often experience depression, functional deterioration, reduction in mobility and life roles, and a lack of professional and social support. ${ }^{3,4}$ However, current rehabilitation care mainly focuses on improving physical functioning, while the difficulties encountered in daily life, the psychosocial consequences poststroke, receive less attention. ${ }^{3,5}$ Clearly, relying solely on hospital or institutional rehabilitation services is costly and unsustainable. To respond to these challenges, priority must be given to rehabilitation strategies that support stroke survivors to maximize their full potentials to manage their health and lives after hospital discharge so as to live a complete and independent life as much as possible. Empowering stroke survivors in self-management poststroke could be a more cost-effective approach.

Self-management was defined by Barlow et $\mathrm{al}^{6}$ as "an individual's ability to manage the symptoms, treatment, physical and psychosocial consequences, and lifestyle changes inherent with living with a chronic disease". Health professionals communicate with patients on their self-management options and support them in dealing with ongoing challenges while living with the chronic disabling condition. $^{3}$ Considerable evidence supports the effectiveness of self-management interventions for chronic diseases (eg, cardiovascular disease, arthritis, diabetes) in producing favorable behavioral and health outcomes. ${ }^{3,7-9}$ Promoting the engagement of stroke survivors in self-management has become an emerging priority because of the increased recognition of the chronic nature of stroke and its related disabling consequences and poststroke sequela. The potential application of self-management interventions for stroke survivors has attracted research interest in recent years. However, to date, the evidence base for self-management in poststroke care is still very limited. A systematic review by Lennon et $\mathrm{al}^{10}$ on poststroke self-management interventions found significant findings in six of nine fair-quality randomized controlled studies with favorable outcomes on disability measures, confidence in recovery, quality of life, and physical functioning in the intervention group (IG). The authors suggested that more high-quality randomized controlled trials were warranted to identify an effective intervention to foster self-management poststroke.
Empowerment is a process that facilitates participation in health and health care decisions and is manifested in awareness of choices to participate in change and self-management behavior, ultimately promoting the well-being of the individual. ${ }^{11}$ The theory of health empowerment proposed by Shearer ${ }^{11}$ views empowerment as a relational process emerging from recognition of personal and social contextual resources for individuals who have limited awareness of and access to these resources. The theory was primarily developed for homebound older adults, and pilot findings supported its efficacy. ${ }^{12}$ According to Shearer, ${ }^{11}$ personal resources include the unique characteristics of individuals, while social-contextual resources are obtained from social networks and social services. Among stroke survivors, selfefficacy is the most extensively studied personal resource and was found to be associated with various outcomes poststroke, including quality of life, depression, activities of daily living, and physical functioning. ${ }^{13,14}$ Self-efficacy was defined by Bandura ${ }^{15}$ as the confidence in an individual's ability to perform a particular behavior. It is a behavior-specific psychological construct. As for social-contextual resources, stroke survivors and their caregivers expressed a high unmet need for professional support of self-management after discharge from hospital. ${ }^{16-18}$ Nurses act as an important source of professional support during the transition from hospital to home, as they work alongside patients and have closer contact with them and their families during poststroke rehabilitation. ${ }^{16}$

Based on Shearer's theory of health empowerment, we developed a nurse-led 13-week Health Empowerment Intervention for Stroke Self-management (HEISS) to foster patients' inner resources (self-efficacy) and socialcontextual resources (supportive relationships) to enhance self-management poststroke. The aim of the study was to examine the effect of the HEISS on self-efficacy, selfmanagement behavior, and functional outcomes compared with a control group $(\mathrm{CG})$ receiving usual care.

\section{Methods \\ Study design}

This is a two-arm single-blind randomized controlled trial (Clinical trials registration: ISRCTN08913646). Stroke survivors were randomized into equally sized control and intervention conditions, using a computer-generated block randomization of 6 . Allocation sequence was generated using sequentially numbered and opaque sealed envelopes. Group assignment was done by independent research personnel who did not involve in the generation of the randomization schedule, the recruitment of patients, and data collection. Patients in CG 
received the usual care customarily provided by the ambulatory stroke rehabilitation program, predominantly including physiotherapy, occupational therapy, and patient education. Patients in IG received the HEISS in addition to usual care.

\section{Participants}

Stroke survivors attending the Ambulatory Rehabilitation Centre of a subacute hospital were recruited. A total of 419 patients were screened for eligibility, including adults who had experienced a first stroke either hemorrhagic or ischemic, were scheduled for the ambulatory stroke rehabilitation, and experienced poststroke functional difficulties that limited self-care. Stroke survivors with aphasia, cognitive impairment (mini-mental state examination score $<18$ ), coexisting severe/life-limiting diseases, premorbid activities of daily living (ADL) dependence, diagnosed with depression, or on antidepressive treatments were excluded. The study was approved by the Hong Kong East Cluster Human Ethics Committee. Written informed consent was obtained from each participant before the study started.

Sample size calculations were based on published Cohen's effect sizes $(d)$ of similar interventions on the outcome variables of interest including self-efficacy, self-management behavior, and self-care, ranging from 0.4 to $0.5,{ }^{19} 0.7,{ }^{20}$ and 0.5 to $0.6,{ }^{19}$ respectively. For conservative sample size estimation, the smallest effect size was adopted. It is estimated that 105 subjects per study arm would produce $80 \%$ power at $5 \%$ level of significance to detect a mean difference of 0.4 standard deviation in self-efficacy score between the IG and CG at posttest (T1), assuming no between-group difference exists in this outcome measure at baseline after randomization and allowing for a $20 \%$ dropout rate.

\section{Intervention}

Participants in IG received the HEISS in addition to usual care. The intervention aimed to empower stroke survivors with "how to" knowledge and skills to enhance self-management in conjunction with their poststroke rehabilitation journey. The HEISS consisted of two parts: part 1 had 6-weekly small group sessions from week 3 to week 8 in parallel with the ambulatory rehabilitation schedule (usual care); groups of four to six participants were given an opportunity to establish a partnership with the nurse facilitator for stroke self-management to begin personal goal setting and action planning. Self-efficacy activities to develop self-management skills and articulating participants' health needs with their personal resources for goal attainment were provided through mastery, verbal persuasion, vicarious experience, and physiological feedback. ${ }^{13}$ A mutually agreed-upon personal rehabilitation goal setting and action plan was devised on completion of the 6-weekly group sessions, and participants were given a personal stroke self-management workbook to guide their implementation at home.

Part 2 included the home-based implementation during weeks 9-13 with biweekly telephone follow-up calls to the participants during this period. The purpose of the telephone follow-up was to encourage and commend participants on their actions for positive changes and to provide problemsolving skills to overcome any perceived barriers that participants encountered. The protocol for the telephone follow-up calls was adapted from Eakin et al. ${ }^{21}$ The nurse facilitator provided feedback with a series of self-management steps and problem-solving strategies to strengthen confidence and motivation. Adherence to or deviations from the agreed action plan in current behavior were addressed to identify the facilitating factors or barriers for change. Table 1 summarizes key components of the HEISS.

\section{Outcome measures}

\section{Self-efficacy and self-management behavior}

Self-efficacy and self-management behavior were assessed using the Chinese Self-Management Behavior Questionnaire originally developed by Lorig and translated and validated by Siu et $\mathrm{al}^{22}$ in Hong Kong. It includes 1) self-efficacy in illness management (six items), 2) cognitive symptom management (six items), and 3) communication with physicians (three items). Each of the subscale components on self-efficacy was measured on a Likert scale to examine the frequency of a specific form of self-management behavior. The questionnaire shows internal consistency with a Cronbach's alpha ranging from 0.72 to 0.91 and retest reliability $r=0.62-0.80 .^{22}$ A further two components applicable to indicators of stroke self-management were added: medication adherence (four items) ${ }^{23}$ and self-blood pressure (BP) monitoring (two items).

\section{Functional outcomes}

For functional ability outcomes, two instruments were used: the modified Barthel index (BI) ${ }^{24}$ and Chinese Lawton instrumental ADL (IADL). ${ }^{25}$ The BI assesses basic ADL performance on a personal level. This ten-item scale gives a summative score with a maximum of 100 , higher scores indicating higher levels of independence in personal self-care activities. The reported Cronbach's alpha ranged from 0.87 to 0.92 , test-retest reliability had $r=0.89$, and concurrent validity was assessed with the index of motor ability 
Table I HEISS empowerment sessions for stroke self-management

\begin{tabular}{|c|c|c|}
\hline Sessions & Topics & Objectives \\
\hline \multicolumn{3}{|l|}{ Small group session ${ }^{\mathrm{a}}$} \\
\hline I (week 3) & Sharing the stroke journey & $\begin{array}{l}\text { - Ice-breaking session to initiate a patient-nurse partnership } \\
\text { - Identify personal strengths and limitations poststroke } \\
\text { - Identify a support person for practicing self-management (rehabilitation } \\
\text { buddy) }\end{array}$ \\
\hline 2 (week 4) & Becoming stroke-safe for life & $\begin{array}{l}\text { - Recognize stroke-warning signs and treatment-seeking action } \\
\text { - Partner with the nurse facilitator to identify lifestyle changes and self-BP } \\
\text { monitoring for secondary stroke prevention } \\
\text { - Set mutually agreed behavioral goals and action plan for home-based } \\
\text { self-management practice }\end{array}$ \\
\hline 3 (week 5) & Becoming active after stroke & $\begin{array}{l}\text { - Explore physical abilities and limitations in self-care or recreational } \\
\text { activities selection } \\
\text { - Partner with the nurse facilitator to develop realistic home-based self-care/ } \\
\text { activities plan by incorporating participant's choice and preferences and } \\
\text { accident precaution }\end{array}$ \\
\hline 4 (week 6) & $\begin{array}{l}\text { Chronic symptoms } \\
\text { recognition and management }\end{array}$ & $\begin{array}{l}\text { - Explore patterns of poststroke physical and emotional symptoms } \\
\text { - Partner with a nurse facilitator to develop chronic symptom monitoring } \\
\text { and management plan by incorporating participant's choice and preferences }\end{array}$ \\
\hline 5 (week 7) & Roads to stroke recovery & $\begin{array}{l}\text { - Share experiences for facilitating factors/barriers and discuss problem- } \\
\text { solving strategies } \\
\text { - Partner with the nurse facilitator to compile a personal stroke } \\
\text { self-management workbook with mutually agreed goals and action plan }\end{array}$ \\
\hline 6 (week 8) & $\begin{array}{l}\text { Consolidation, sharing, and } \\
\text { feedback }\end{array}$ & $\begin{array}{l}\text { - Report on and share home-based self-management experience } \\
\text { - Acknowledge goal attainments by positive reinforcement } \\
\text { - Discuss problem-solving and required change/fine tuning of action plan } \\
\text { in the workbook relevant to identified barriers } \\
\text { - Consolidate mid-term goal setting and action plan for home-based } \\
\text { implementation }\end{array}$ \\
\hline \multicolumn{3}{|l|}{ Telephone follow-up } \\
\hline $\begin{array}{l}\text { Biweekly individual telephone } \\
\text { session (week } 9 \text { to week 13) }\end{array}$ & $\begin{array}{l}\text { Individual feedback for } \\
\text { home-based implementation }\end{array}$ & $\begin{array}{l}\text { - Assess consistency of or deviation from personal rehabilitation goals } \\
\text { and action plan } \\
\text { - Provide reinforcement on positive changes } \\
\text { - Explore problem-solving/alternatives to overcome perceived/actual } \\
\text { barriers }\end{array}$ \\
\hline
\end{tabular}

Note: ${ }^{a}$ The HEISS commenced in week 3 because all stroke patients (both CG and IG) had to attend two health talk sessions in week I and week 2 (usual care in the ambulatory rehabilitation schedule).

Abbreviations: BP, blood pressure; CG, control group; HEISS, Health Empowerment Intervention for Stroke Self-management; IG, intervention group.

at $0.77 .{ }^{24}$ The nine-item Chinese Lawton IADL scale was used to assess extended ADL performance on independent living. The reported Cronbach's alpha of the IADL score was $0.86,{ }^{25}$ higher scores indicating higher levels of independence.

\section{Data collection procedures}

Outcome measures were collected through researcheradministered questionnaires at four time points: pretest (T0), 1 week posttest (T1, the week after HEISS), 3 months posttest (T2), and 6 months posttest (T3). Demographic, clinical, and lifestyle data were collected from self-reports and medical records. Two independent research assistants were trained for data collection according to a standardized protocol. Interrater reliability ranged from 0.88 to 1.0 . Adhering to the single-blind method, the two research assistants were blinded to study design and group allocation.

\section{Data analysis}

The intention-to-treat principle was adopted for data analysis. Baseline demographic and clinical data between CG and IG were compared using independent $t$-test, chi-square test, or Fisher's exact test where appropriate. Generalized estimating equation (GEE) models were used to assess differential changes in each outcome variable between two groups across the time points T0, T1, T2, and T3. Dummy variables representing group and time points were assigned to correspond the IG with $\mathrm{CG}$ as the reference and to correspond $\mathrm{T} 1, \mathrm{~T} 2$, and $\mathrm{T} 3$ with the baseline (T0) as the reference. The interaction terms for group and time point dummy variables were included in the GEE models to assess the differential changes of the outcome variables at each posttest time point with respect to the baseline between the two groups. All statistical analyses were performed using IBM SPSS 22 (IBM Corporation, 
Armonk, NY, USA). All statistical tests were two-sided, and a $P$-value $<0.05$ was regarded as statistically significant.

\section{Results}

A total of 210 stroke patients enrolled to the study. The participant recruitment, randomization, and retention flowchart for the study is shown in Figure 1. The overall dropout rate was $16.7 \%$, with $11.4 \%$ for IG and $21.9 \%$ for CG. Demographic, lifestyle, and clinical characteristics between completers and those who dropped-out were compared, with no statistically significant differences found.

Stroke survivors in this study were predominately older adults with a mean age of 69 years old $(\mathrm{SD}=14.1)$. Of these, $31.9 \%$ were $<65$ years, $52.4 \%$ were males, and the majority were married (72.4\%). All participants required assistance from caregivers after the stroke mainly (87.6\%) provided by informal caregivers (either relatives or paid domestic helpers). The majority (72\%) of participants suffered from ischemic stroke, which resulted in hemiparesis (89\%) and tactile sensory impairment $(63 \%) .{ }^{26}$ Seventy percent of the stroke participants reported hypertension before the stroke. The IG and CG participants' demographic characteristics and clinical profile were compared, with no statistically significant difference was found, apart from IG participants reported more heart disease (Table 2).

Table 3 shows the mean score of the outcome variables: self-efficacy in illness management, self-management behaviors, and functional ability across the baseline (T0) and three

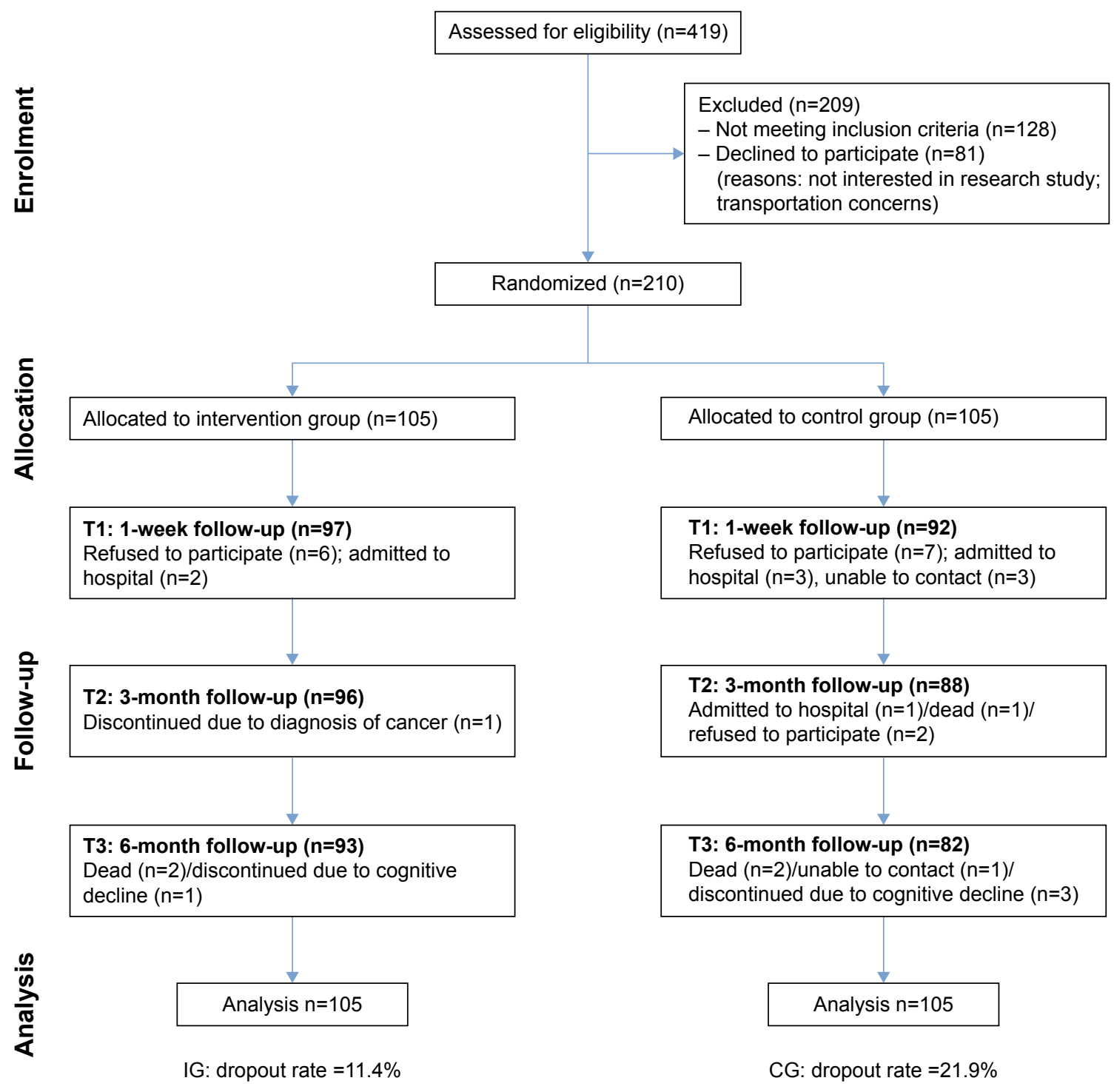

Overall dropout rate $=16.7 \%$

Figure I Flow diagram of participant recruitment.

Abbreviations: CG, control group; IG, intervention group. 
Table 2 Baseline sociodemographic characteristics and clinical profile of participants $(\mathrm{N}=210)$

\begin{tabular}{|c|c|c|c|c|}
\hline Characteristics & $\begin{array}{l}\text { Control } \\
(n=105)\end{array}$ & $\begin{array}{l}\text { Intervention } \\
(n=105)\end{array}$ & $\begin{array}{l}\text { Statistic } \\
\text { value }\end{array}$ & $P$-value \\
\hline Age (years) ${ }^{a}$ & 70.7 (I3.9) & $67.8(14.2)$ & 1.543 & $0.124^{\mathrm{b}}$ \\
\hline \multicolumn{5}{|l|}{ Sex } \\
\hline Male & $55(52.4)$ & $55(52.4)$ & 0.000 & 0.999 \\
\hline Female & $50(47.6)$ & $50(47.6)$ & & \\
\hline \multicolumn{5}{|l|}{ Marital status } \\
\hline Single & $10(9.6)$ & $10(9.5)$ & 3.289 & 0.193 \\
\hline Married & $80(76.2)$ & 7I (67.6) & & \\
\hline $\begin{array}{l}\text { Divorced/ } \\
\text { separated/widowed }\end{array}$ & $15(14.2)$ & $24(22.9)$ & & \\
\hline \multicolumn{5}{|l|}{ Educational level } \\
\hline $\begin{array}{l}\text { No formal } \\
\text { education }\end{array}$ & $22(20.9)$ & $21(20.0)$ & 1.842 & 0.606 \\
\hline Primary school & $27(25.7)$ & $24(22.9)$ & & \\
\hline Secondary school & $47(44.7)$ & $46(43.8)$ & & \\
\hline Tertiary or above & $9(8.7)$ & $14(13.3)$ & & \\
\hline \multicolumn{5}{|l|}{ Employment status } \\
\hline Full/part-time work & $34(32.4)$ & $33(31.4)$ & 0.893 & 0.827 \\
\hline Housewife & $15(14.3)$ & $20(19.0)$ & & \\
\hline Retired & $48(45.7)$ & $45(42.9)$ & & \\
\hline Unemployed & $8(7.6)$ & $7(6.7)$ & & \\
\hline \multicolumn{5}{|l|}{ Carer } \\
\hline Relatives & $17(16.2)$ & $24(22.9)$ & 6.503 & 0.090 \\
\hline $\begin{array}{l}\text { Paid full-time } \\
\text { domestic helper }\end{array}$ & $10(9.6)$ & $16(15.2)$ & & \\
\hline $\begin{array}{l}\text { Paid part-time } \\
\text { domestic helper }\end{array}$ & $60(57.1)$ & $57(54.3)$ & & \\
\hline Aged care staff & $18(17.1)$ & $8(7.6)$ & & \\
\hline \multicolumn{5}{|l|}{ Religion } \\
\hline No & $62(59.1)$ & $61(58.1)$ & 0.007 & 0.935 \\
\hline Yes & $43(40.9)$ & $44(41.9)$ & & \\
\hline \multicolumn{5}{|l|}{ Smoking habits } \\
\hline Never smoke & $68(64.8)$ & $68(64.8)$ & 0.288 & $0.999^{c}$ \\
\hline Ex-smoker & $34(32.3)$ & $35(33.3)$ & & \\
\hline Smoker & $3(2.9)$ & $2(1.9)$ & & \\
\hline \multicolumn{5}{|l|}{ Stroke type } \\
\hline Hemorrhagic & $27(25.7)$ & $29(27.6)$ & 0.667 & 0.754 \\
\hline Ischemic & $78(74.3)$ & $76(72.4)$ & & \\
\hline \multicolumn{5}{|l|}{ Affected brain region } \\
\hline Left & 49 (46.7) & $4 I(40.2)$ & 1.086 & $0.579^{c}$ \\
\hline Right & $52(49.5)$ & 57 (55.9) & & \\
\hline Both & $4(3.8)$ & $4(3.9)$ & & \\
\hline \multicolumn{5}{|l|}{ Mobility } \\
\hline Hemiplegia & $6(5.7)$ & $4(3.8)$ & 1.467 & $0.854^{c}$ \\
\hline Hemiparesis & $90(85.7)$ & $92(88.5)$ & & \\
\hline Both & $8(7.6)$ & $7(6.7)$ & & \\
\hline Not obvious & $\mathrm{I}(\mathrm{I} .0)$ & I (I.0) & & \\
\hline \multicolumn{5}{|l|}{ Affected body part } \\
\hline Left side & $49(46.6)$ & $50(47.6)$ & 0.442 & 0.961 \\
\hline Right side & 41 (39.I) & $4 \mid(39.0)$ & & \\
\hline Both & $9(8.6)$ & $9(8.6)$ & & \\
\hline $\begin{array}{l}\text { Others (visual/ } \\
\text { speech) }\end{array}$ & $6(5.7)$ & $5(4.8)$ & & \\
\hline \multicolumn{5}{|l|}{ Sensory influence } \\
\hline Intact & $35(33.3)$ & $35(33.3)$ & 0.181 & $0.996^{c}$ \\
\hline Impaired & $65(61.9)$ & $66(62.9)$ & & \\
\hline Absent & $5(4.8)$ & $4(3.8)$ & & \\
\hline
\end{tabular}

(Continued)
Table 2 (Continued)

\begin{tabular}{|c|c|c|c|c|}
\hline Characteristics & $\begin{array}{l}\text { Control } \\
(n=105)\end{array}$ & $\begin{array}{l}\text { Intervention } \\
(n=105)\end{array}$ & $\begin{array}{l}\text { Statistic } \\
\text { value }\end{array}$ & $P$-value \\
\hline Chronic illnesses & $96(91.4)$ & $93(90.3)$ & 0.476 & 0.490 \\
\hline Hypertension & $74(70.5)$ & $73(70.9)$ & 0.023 & 0.880 \\
\hline Diabetes mellitus & $38(36.2)$ & $36(35.0)$ & 0.083 & 0.773 \\
\hline Hyperlipidemia & $47(44.8)$ & $50(48.5)$ & 0.172 & 0.678 \\
\hline Heart disease & II (I0.5) & $24(23.3)$ & 5.794 & 0.016 \\
\hline Complications & $7(7.0)$ & $13(12.7)$ & 1.989 & 0.158 \\
\hline
\end{tabular}

Notes: Data are presented as frequencies (\%) unless stated otherwise. ${ }^{\text {DData }}$ are presented as mean (standard deviation); between-group comparison was performed by Student's $t$-test. Categorical variables were compared between the two groups using Pearson's chi-square test, those marked 'c' were compared using Fisher's exact test.

postintervention time points, 1 week (T1), 3 months (T2), and 6 months (T3). ${ }^{26}$

To evaluate the differential changes of each of the outcome variables across the time points (T1, T2, and T3 with $\mathrm{T} 0$ as the comparison) between IG and CG, a GEE model was used, which can take into account baseline outcome values and the intracorrelation of the repeated measures outcome across time. The differential changes in each outcome variable were assessed by the regression coefficients of the group by time point interaction terms in the model. Table 4 shows the outcome results of the GEE model. Participants in IG showed more favorable improvements in all outcomes at all postintervention time points, than those in CG.

In particular, IG had significantly better self-efficacy in illness management at 3-month (T2) and 6-month (T3) postintervention ( $P=0.011$ and $P=0.012$, respectively) than CG. In the four outcomes used to assess self-management behaviors (ie, cognitive symptom management, communication with physician, medication adherence, self-BP monitoring), significantly better cognitive symptom management was reported by those in IG across all three time points (all $P<0.001$ ) than CG. Stroke survivors in IG reported significantly better communication with their physicians at T1 $(P<0.001)$ and T2 $(P=0.002)$ compared to $\mathrm{CG}$, but no significant difference between groups was observed at T3 $(P=0.094)$. There was no significant difference in medical adherence between IG and CG, for any of the postintervention time points (all $P>0.05$ ). However, those in IG reported significantly better self-BP monitoring at all three postintervention time points (odds ratios of the group by time point interaction terms at T1, T2, and T3 were $P=0.005, P=0.005$, and $P=0.025$, respectively) than those in CG (Table 4).

Functional ability among the IG participants had significant improvement in ADLs according to the $\mathrm{BI}(P=0.005$, $P=0.016$, and $P=0.03$ at T1, T2, and T3, respectively), when compared to those in CG. When examining IADLs using 
Table 3 Primary and secondary outcomes of control and intervention groups across time

\begin{tabular}{|c|c|c|c|c|c|c|c|c|}
\hline \multirow[t]{2}{*}{ Outcomes } & \multicolumn{2}{|c|}{ T0 (the baseline) } & \multicolumn{2}{|c|}{ TI (I week posttest) } & \multicolumn{2}{|c|}{ T2 (3 months posttest) } & \multicolumn{2}{|c|}{ T3 (6 months posttest) } \\
\hline & $\begin{array}{l}\text { Control } \\
(n=105)\end{array}$ & $\begin{array}{l}\text { Intervention } \\
(n=105)\end{array}$ & $\begin{array}{l}\text { Control } \\
(n=92)\end{array}$ & $\begin{array}{l}\text { Intervention } \\
(\mathrm{n}=97)\end{array}$ & $\begin{array}{l}\text { Control } \\
(n=88)\end{array}$ & $\begin{array}{l}\text { Intervention } \\
(n=96)\end{array}$ & $\begin{array}{l}\text { Control } \\
(n=82)\end{array}$ & $\begin{array}{l}\text { Intervention } \\
(\mathrm{n}=93)\end{array}$ \\
\hline \multicolumn{9}{|l|}{ Self-efficacy } \\
\hline $\begin{array}{l}\text { Self-efficacy in illness } \\
\text { management }\end{array}$ & $35.2(15.0)$ & $37.4(12.9)$ & $36.7(15.0)$ & $40.9(13.4)$ & $35.5(15.1)$ & $42.8(13.5)$ & $36.7(14.8)$ & $44.2(12.3)$ \\
\hline \multicolumn{9}{|l|}{ Self-management behavior } \\
\hline $\begin{array}{l}\text { Cognitive symptom } \\
\text { management }\end{array}$ & $9.0(5.9)$ & $8.4(4.8)$ & $9.6(5.8)$ & $13.6(6.5)$ & $9.5(5.9)$ & I4.I (6.5) & $9.0(5.7)$ & $12.1(6.5)$ \\
\hline $\begin{array}{l}\text { Communication with } \\
\text { physician }\end{array}$ & $3.4(2.8)$ & $3.4(3.2)$ & $4.9(4.3)$ & $8.4(5.5)$ & $5.2(4.7)$ & $7.7(5.6)$ & $5.7(4.4)$ & $7.0(5.4)$ \\
\hline Medication adherence ${ }^{\mathrm{a}}$ & $75(72.1)$ & $76(72.4)$ & $69(75.0)$ & $74(77.1)$ & $65(73.9)$ & $75(78.1)$ & $68(81.0)$ & $66(71.0)$ \\
\hline Self-BP monitoring record ${ }^{a}$ & $45(42.9)$ & $45(42.9)$ & $50(54.9)$ & $72(75.0)$ & $48(54.5)$ & 71 (75.5) & $47(58.8)$ & $70(77.8)$ \\
\hline \multicolumn{9}{|l|}{ Functional ability } \\
\hline $\mathrm{BI}$ & $75.8(22.0)$ & $72.6(22.9)$ & $84.5(19.0)$ & $86.6(19.5)$ & $83.2(21.9)$ & $88.3(20.9)$ & $82.2(26.3)$ & $86.3(24.9)$ \\
\hline Lawton IADL scale & $7.7(5.5)$ & $7.0(4.4)$ & $9.1(6.2)$ & II.I (5.3) & $8.4(6.1)$ & II.6 (5.3) & $9.5(6.2)$ & II.8 (5.6) \\
\hline
\end{tabular}

Notes: Data are presented as mean (standard deviations) unless stated otherwise. ${ }^{\mathrm{a}}$ Data are presented as frequencies (\%).

Abbreviations: BI, Barthel index; BP, blood pressure; IADL, instrumental activities of daily living.

the Lawton's measure, those in IG had significantly better improvement across all three postintervention time points (all $P<0.001$ ) at T1, T2, and T3, respectively, compared to CG (Table 4).

\section{Discussion}

This study assessed the effects of HEISS on self-management during the ambulatory stroke rehabilitation phase. Study results indicate that the HEISS was effective in improving self-efficacy in illness management, self-management behaviors (cognitive symptom management, communication with physician, and self-BP monitoring), and functional recovery (BI and Lawton index), compared to controls.

When compared with baseline data, the effect of HEISS on improving self-management was more prominent at the T1 (1 week posttest) and T2 (3 months posttest) and waning slightly by T3 (6 months posttest). This finding suggests that the beneficial effects of the HEISS intervention were

Table 4 GEE models for outcomes comparison across time between control and intervention groups

\begin{tabular}{|c|c|c|c|c|c|c|c|}
\hline \multirow[t]{2}{*}{ Outcomes } & \multicolumn{7}{|c|}{ Regression coefficients of the GEE models } \\
\hline & $\begin{array}{l}\text { Group } \\
\text { B (95\% Cl) }\end{array}$ & $\begin{array}{l}\text { TI } \\
\text { B (95\% Cl) }\end{array}$ & $\begin{array}{l}\text { T2 } \\
\text { B }(95 \% \mathrm{Cl})\end{array}$ & $\begin{array}{l}\text { T3 } \\
\text { B (95\% Cl) }\end{array}$ & $\begin{array}{l}\text { Group } \times \text { TI } \\
\text { B }(95 \% \mathrm{Cl})\end{array}$ & $\begin{array}{l}\text { Group } \times \text { T2 } \\
\mathrm{B}(95 \% \mathrm{Cl})\end{array}$ & $\begin{array}{l}\text { Group } \times \text { T3 } \\
\text { B }(95 \% \mathrm{Cl})\end{array}$ \\
\hline \multicolumn{8}{|l|}{ Self-efficacy } \\
\hline $\begin{array}{l}\text { Self-efficacy in illness } \\
\text { management }\end{array}$ & $\begin{array}{l}2.24 \\
(-1.52,6.01)\end{array}$ & $\begin{array}{l}1.10 \\
(-1.66,3.85)\end{array}$ & $\begin{array}{l}-0.47 \\
(-3.57,2.63)\end{array}$ & $\begin{array}{l}0.42 \\
(-2.96,3.80)\end{array}$ & $\begin{array}{l}2.11 \\
(-1.77,6.00)\end{array}$ & $\begin{array}{l}5.44 \\
(1.24,9.64)^{*}\end{array}$ & $\begin{array}{l}5.59 \\
(1.22,9.95)^{*}\end{array}$ \\
\hline \multicolumn{8}{|l|}{ Self-management behavior } \\
\hline $\begin{array}{l}\text { Cognitive symptom } \\
\text { management }\end{array}$ & $\begin{array}{l}-0.57 \\
(-2.01,0.87)\end{array}$ & $\begin{array}{l}0.56 \\
(-0.70,1.82)\end{array}$ & $\begin{array}{l}0.40 \\
(-0.84,1.65)\end{array}$ & $\begin{array}{l}-0.21 \\
(-1.65,1.23)\end{array}$ & $\begin{array}{l}4.49 \\
(2.60,6.37)^{* * *}\end{array}$ & $\begin{array}{l}5.18 \\
(3.27,7.09) * * *\end{array}$ & $\begin{array}{l}3.61 \\
(1.62,5.61)^{* * *}\end{array}$ \\
\hline $\begin{array}{l}\text { Communication with } \\
\text { physician }\end{array}$ & $\begin{array}{l}-0.03 \\
(-0.84,0.78)\end{array}$ & $\begin{array}{l}\text { I.44 } \\
(0.60,2.28) * * *\end{array}$ & $\begin{array}{l}1.78 \\
(0.78,2.77)^{* * *}\end{array}$ & $\begin{array}{l}2.23 \\
(1.17,3.29) * * *\end{array}$ & $\begin{array}{l}3.53 \\
(2.13,4.94) * * *\end{array}$ & $\begin{array}{l}2.44 \\
(0.93,3.95) * *\end{array}$ & $\begin{array}{l}1.36 \\
(-0.23,2.95)\end{array}$ \\
\hline Medication adherence ${ }^{\mathrm{a}}$ & $\begin{array}{l}1.01 \\
(0.55,1.86)\end{array}$ & $\begin{array}{l}1.15 \\
(0.69,1.90)\end{array}$ & $\begin{array}{l}1.04 \\
(0.59,1.82)\end{array}$ & $\begin{array}{l}1.61 \\
(0.87,2.99)\end{array}$ & $\begin{array}{l}1.10 \\
(0.50,2.42)\end{array}$ & $\begin{array}{l}1.29 \\
(0.57,2.92)\end{array}$ & $\begin{array}{l}0.57 \\
(0.25,1.32)\end{array}$ \\
\hline Self-BP monitoring ${ }^{\mathrm{a}}$ & $\begin{array}{l}1.00 \\
(0.58,1.73)\end{array}$ & $\begin{array}{l}1.55 \\
(1.04,2.30)^{*}\end{array}$ & $\begin{array}{l}1.54 \\
(0.98,2.40)\end{array}$ & $\begin{array}{l}1.83 \\
(1.12,2.98)^{*}\end{array}$ & $\begin{array}{l}2.49 \\
(1.32,4.68)^{* *}\end{array}$ & $\begin{array}{l}2.56 \\
(1.32,4.96)^{* *}\end{array}$ & $\begin{array}{l}2.31 \\
(1.11,4.8 I)^{*}\end{array}$ \\
\hline \multicolumn{8}{|l|}{ Functional ability } \\
\hline $\mathrm{BI}$ & $\begin{array}{l}-3.24 \\
(-9.28,2.80)\end{array}$ & $\begin{array}{l}8.46 \\
(5.15,11.77)^{* * *}\end{array}$ & $\begin{array}{l}6.98 \\
(2.44,11.53)^{* *}\end{array}$ & $\begin{array}{l}5.48 \\
(0.80,10.16)^{*}\end{array}$ & $\begin{array}{l}5.20 \\
(0.75,9.64)^{*}\end{array}$ & $\begin{array}{l}8.04 \\
(2.40,13.68)^{* *}\end{array}$ & $\begin{array}{l}7.97 \\
(1.51,14.43)^{*}\end{array}$ \\
\hline Lawton IADL scale & $\begin{array}{l}-0.65 \\
(-1.98,0.69)\end{array}$ & $\begin{array}{l}1.56 \\
(0.67,2.44)^{* *}\end{array}$ & $\begin{array}{l}0.92 \\
(-0.05,1.89)\end{array}$ & $\begin{array}{l}1.80 \\
(0.66,2.93)^{* *}\end{array}$ & $\begin{array}{l}2.46 \\
(1.29,3.63) * * *\end{array}$ & $\begin{array}{l}3.54 \\
(2.27,4.80) * * *\end{array}$ & $\begin{array}{l}2.86 \\
(1.39,4.32) * * *\end{array}$ \\
\hline
\end{tabular}

Notes: TI, I-week posttest;T2, 3-month posttest;T3, 6-month posttest. Only the model estimates of regression coefficients of the dummy variables for the group (Group: $0=$ control [reference]; I= intervention), time points (TI,T2, and T3 with the baseline [T0] as reference), and time points and group interaction terms (Group $\times$ TI, Group $\times$ T2, and Group $\times$ T3) are shown for the GEE models. ${ }^{2}$ The binary outcomes were entered into GEE models with the use of binary logistic link function, and the regression coefficients are presented as odds ratio. $* P<0.05 ; * * P<0.01 ; * * * P<0.001$.

Abbreviations: $\mathrm{BI}$, Barthel index; BP, blood pressure; Cl, confidence interval; GEE, generalized estimating equation; IADL, instrumental activities of daily living. 
stronger during the earlier two time points. The explanation for the reduced effect at T3 could possibly lie in patients' gradual recovery of mobility or a gain of confidence, leading to adaptations with their poststroke recovery. On the other hand, it could be that less contact with health professionals and no booster reinforcement 6 months after the intervention may partly explain this reduced effect. Self-management behavior in improved medication adherence was not found. This may have been due to more vigilant medication compliance on the part of both groups, especially after a major health event such as a stroke. Moreover, medication adherence has always been a major focus of patient education in stroke rehabilitation in Hong Kong (usual care); thus, participants in the CG may have received strategies for enhancing medication adherence, which may partly explain the lack of a significant difference between groups.

According to Bandura's ${ }^{27}$ social cognitive model, selfefficacy is defined as a psychological construct that describes people's belief in their own ability to perform and succeed in a particular situation. It can be improved through mastering an activity and by observing others performing a task. Peer influence and support during the rehabilitation period are important, enabling stroke patients with similar disabilities to work together and motivate one another to deal with a difficult activity or task. Positive encouragement through verbal persuasion from health care personnel during HEISS can also help to motivate participants little by little, in a gently progressive manner. Also, during small group sessions, acknowledgment by nurses and peers of small achievements further strengthens a person's self-efficacy and thus positively reinforces self-management behavior.

Our findings are in line with Johnston et al, ${ }^{28}$ suggesting that improvement in self-efficacy may produce more longterm value in sustaining stroke survivors' belief in their own capabilities to overcome the negative impact of stroke. It is possible that during the course of recovery, those in HEISS experienced improved self-efficacy over time than those not receiving the intervention.

The BI and Lawton IADL are measures of functional aspects of daily living. The BI for the CG improved over time with slight fluctuation over the three time points, whereas the IG's improvement was more significant over these periods. A similar observation was applied to the IADL measure, whereas a more stable improvement was seen in the IG. It is suggested that the IG's steady improvement in functional ability reflected the positive effects of HEISS in this group of stroke survivors. Possible explanation for the functional gain in ADL could be that, in HEISS, the behavioral goals and action plans that are relevant to the activity limitation domain after stroke consist primarily of self-care tasks in ADL. The empowerment process of HEISS enabled participants to set personal goals and action plan for day-to-day self-care activities, as well as developed their problem-solving ability and resource utilization for goals attainment. Furthermore, congruent with improvements in self-efficacy in illness management over time, HEISS participants possibly experienced success in day-to-day illness management and become more able to minimize the negative impacts of physical symptoms on performing ADL. The results of this study are in line with those of previous studies where the positive effects of stroke self-management programs on functional outcomes were reported..$^{19,28-30}$ On the other hand, the fluctuations observed in the $\mathrm{CG}$ (both $\mathrm{BI}$ and IADL) are possibly related to variation in day-to-day illness management ability and coping when faced with difficulties or physical symptoms.

Interpretation of the findings should take into consideration the limitations of this study. First, the intervention adopted a multifaceted approach; therefore, the specific component in HEISS that was effective could not be readily determined. Second, the positive changes reported by the participants in the IG could have resulted from different intensity levels of professional attention received by the two groups, even though similar nurse-patient time was scheduled for face-to-face and telephone contact to balance the attention effects for those in the CG. Third, self-management behavior was assessed using self-report. This might have led to overreporting of what was seen as desired behavior by the participants, despite the measures put in place to reduce social desirable tendencies. Finally, the baseline characteristics between those who have completed data collection and those who have dropped-out were essentially comparable, and hence, the dropout cases would unlikely be informative. Nevertheless, there might be potential biases in the study results owing to particularly uneven dropout rates in the two groups. The effects of the intervention might be overestimated if most of the droppedout cases had better outcome measures, or vice versa.

\section{Implications for service planning and health policy}

Stroke is an acute event with long-term chronic disabling consequences requiring nursing and rehabilitation attention beyond the in-patient period. However, continuity and integration between hospital and community care often become challenging. Using ambulatory rehabilitation 
services as a platform, the integration of hospital- and home-based rehabilitative care could be better structured to serve as a bridge for transitional care in stroke survivors' rehabilitation journey. Our findings suggest that stroke patient empowerment intervention could be incorporated into the ambulatory rehabilitation phase, where it becomes more feasible for ongoing professional support could be employed to aid stroke survivors to assume responsibility for and participate in stroke self-management in a home setting. Findings from this study also suggest that implementation of HEISS has the potential to strengthen stroke survivors' self-efficacy in illness management and sustain stroke selfmanagement over the longer term.

\section{Conclusion}

This study demonstrates that health empowerment has moved beyond simply providing patients with the knowledge and skills needed for self-care. Health empowerment is a process of enhancing patients' self-belief, which makes them willing and able to play an active role in managing their own health and exercise influence over events that affect their lives during the stroke rehabilitation journey. We found that the stroke patient empowerment intervention (HEISS) brought added value to the existing ambulatory stroke rehabilitation services as far as functional outcomes were concerned. Our findings suggest that stroke patient empowerment intervention could be incorporated at the ambulatory rehabilitation phase, where the ongoing professional support through nurse-patient partnership may improve continuity of care and produce more effective interface with home-based rehabilitation in the early stroke recovery period.

\section{Acknowledgments}

The authors sincerely thank the stroke survivors who participated in this study. This study was funded by the Health and Medical Research Grant (09100551). Part of findings reported in this paper were presented at the Stroke Nursing Symposium, International Stroke Conference 2016.

\section{Disclosure}

The authors report no conflicts of interest in this work.

\section{References}

1. WHO, editor. Global Status Health Report on Non-Communicable Diseases. Vol 2011. Geneva: WHO; 2010.

2. Hospital Authority [homepage on the Internet]. HA Statistical Report, 2015 [updated 2015]. Available from: www.ha.org.hk. Accessed February 1, 2016.
3. Jones F, Riazi A, Norris M. Self-management after stroke: time for some more questions? Disabil Rehabil. 2013;35(3):257-264.

4. Sit JW, Wong TK, Clinton M, Li LS. Associated factors of post-stroke depression among Hong Kong Chinese: a longitudinal study. Psychol Health Med. 2007;12(2):117-125.

5. Jones F. Strategies to enhance chronic disease self-management: how can we apply this to stroke? Disabil Rehabil. 2006;28(13-14):841-847.

6. Barlow J, Sturt J, Hearnshaw H. Self-management interventions for people with chronic conditions in primary care: examples from arthritis, asthma and diabetes. Health Educ J. 2002;61:365-378.

7. Chodosh J, Morton SC, Mojica W, et al. Meta-analysis: chronic disease self-management programs for older adults. Ann Intern Med. 2005;143(6): 427-438.

8. Scott IA. Chronic disease management: a primer for physicians. Intern Med J. 2008;38(6):427-437.

9. Chan WL, Hui E, Chan C, et al. Evaluation of chronic disease selfmanagement programme (CDSMP) for older adults in Hong Kong. J Nutr Health Aging. 2011;15(3):209-214.

10. Lennon S, McKenna S, Jones F. Self-management programmes for people post stroke: a systematic review. Clin Rehabil. 2013;27(10):867-878.

11. Shearer NB. Health empowerment theory as a guide for practice. Geriatr Nurs. 2009;30(2 suppl):4-10.

12. Crawford Shearer NB, Fleury JD, Belyea M. Randomized control trial of the health empowerment intervention: feasibility and impact. Nurs Res. 2010;59(3):203-211.

13. Jones F, Riazi A. Self-efficacy and self-management after stroke: a systematic review. Disabil Rehabil. 2011;33(10):797-810.

14. Korpershoek C, van der Bij1 J, Hafsteinsdottir TB. Self-efficacy and its influence on recovery of patients with stroke: a systematic review. J Adv Nurs. 2011;67(9):1876-1894.

15. Bandura A. Self-Efficacy: The Exercise of Control. New York, NY: WH Freeman and Company; 1997.

16. Sit JW, Wong TK, Clinton M, Li LS, Fong YM. Stroke care in the home: the impact of social support on the general health of family caregivers. J Clin Nurs. 2004;13(7):816-824.

17. Alaszewski A, Alaszewski H, Potter J. The bereavement model, stroke and rehabilitation: a critical analysis of the use of a psychological model in professional practice. Disabil Rehabil. 2004;26(18):1067-1078.

18. Robison J, Wiles R, Ellis-Hill C, McPherson K, Hyndman D, Ashburn A. Resuming previously valued activities post-stroke: who or what helps? Disabil Rehabil. 2009;31(19):1555-1566.

19. Kendall E, Catalano T, Kuipers P, Posner N, Buys N, Charker J. Recovery following stroke: the role of self-management education. Soc Sci Med. 2007;64(3):735-746.

20. Sit JW, Yip VY, Ko SK, Gun AP, Lee JS. A quasi-experimental study on a community-based stroke prevention programme for clients with minor stroke. J Clin Nurs. 2007;16(2):272-281.

21. Eakin E, Reeves M, Lawler S, et al. Telephone counseling for physical activity and diet in primary care patients. Am J Prev Med. 2009;36(2): $142-149$.

22. Siu AM, Chan CC, Poon PK, Chui DY, Chan SC. Evaluation of the chronic disease self-management program in a Chinese population. Patient Educ Couns. 2007;65(1):42-50.

23. Morisky D, Green L, Levine D. Self-reported medication-taking scale. In: Lorig K, Stewart A, Ritter P, Conzalez V, Laurent D, Lynch J, editors. Outcome Measures for Health Education and Other Health Care Interventions. Thousand Oaks, CA: SAGE Publications Inc; 1996:72.

24. Shah S, Vanclay F, Cooper B. Improving the sensitivity of the Barthel index for stroke rehabilitation. J Clin Epidemiol. 1989;42(8): 703-709.

25. Tong A, Man D. The validation of the Hong Kong Chinese version of the Lawton instrumental activities of daily living scale for institutionalized elderly persons. OTJR (Thorofare $N J$ ). 2002;22(4): $132-142$. 
26. Sit JW, Chair SY, Choi KC, Chan CWH, Ching R, Taylor-Piliae RE, Tang SW. The effects of a theory-based health empowerment intervention on self-management and functional recovery post-stroke. Stroke. 2016;47(Supp1 1), ANS7.

27. Bandura A. Self-efficacy: toward a unifying theory of behavioral change. Psychol Rev. 1977;84(2):191-215.

28. Johnston M, Bonetti D, Joice S, et al. Recovery from disability after stroke as a target for a behavioural intervention: results of a randomized controlled trial. Disabil Rehabil. 2007;29(14):1117-1127.
29. Nir Z, Zolotogorsky Z, Sugarman H. Structured nursing intervention versus routine rehabilitation after stroke. Am J Phys Med Rehabil. 2004; 83(7):522-529.

30. Huijbregts MP, Myers AM, Streiner D, Teasell R. Implementation, process, and preliminary outcome evaluation of two community programs for persons with stroke and their care partners. Top Stroke Rehabil. 2008; 15(5):503-520.

\section{Publish your work in this journal}

Clinical Interventions in Aging is an international, peer-reviewed journal focusing on evidence-based reports on the value or lack thereof of treatments intended to prevent or delay the onset of maladaptive correlates of aging in human beings. This journal is indexed on PubMed Central, MedLine,
CAS, Scopus and the Elsevier Bibliographic databases. The manuscript management system is completely online and includes a very quick and fair peer-review system, which is all easy to use. Visit http://www.dovepress. com/testimonials.php to read real quotes from published authors. 